\title{
Correspondence of measured soil carbon fractions and RothC pools for equilibrium and non-equilibrium states
}

M. Herbst ${ }^{1}$, G. Welp ${ }^{2}$, A. Macdonald ${ }^{3}$, M. Jate ${ }^{4}$, A. Hädicke ${ }^{5}$, H. Scherer ${ }^{6}$, T. Gaiser ${ }^{7}$, F. Herrmann $^{1}$, W. Amelung ${ }^{1,2}$, J. Vanderborght ${ }^{1}$

[1] Agrosphere Institute, IBG-3, Forschungszentrum Jülich GmbH, Germany

[2] Institute of Crop Science and Resource Conservation (INRES), Soil Science and Soil Ecology, University of Bonn, Germany

[3] Sustainable Soils and Grassland Systems Department, Rothamsted Research, Harpenden, Herts, United Kingdom

[4] YARA GmBH \& Co.KG, Research Centre Hanninghof, Dülmen, Germany

[5] Fachbereich 32 - Bodenschutz, Altlasten, Ökotoxikologie -, Landesamt für Natur, Umwelt und Verbraucherschutz NRW, Recklinghausen, Germany

[6] Institute of Crop Science and Resource Conservation (INRES), Plant Nutrition, University of Bonn, Germany

[7] Institute of Crop Science and Resource Conservation (INRES), Crop Science, University of Bonn, Germany

Correspondence to: M. Herbst (m.herbst@fz-juelich.de) 


\begin{abstract}
The link between carbon turnover model pools and measurable carbon fractions is of key interest for initial parameterisation and subsequent validation of dynamic soil carbon models. In this study we performed the established particle-size fractionation of soils from 54 intensively monitored sites in Germany and from archived samples from 5 other long-term experiments in Germany and the United Kingdom. The Rothamsted carbon (RothC) model was then used to compare the measured soil $\mathrm{C}$ fractionation from the 54 intensively monitored sites against modelled pools using spin-up equilibrium runs whilst dynamic (nonequilibrium) model runs were performed when comparing data from the long-term experiments. We detected good agreement between measured soil $\mathrm{C}$ fractions and modelled pools, indicated by correlation coefficients of 0.73 and 0.81 for the resistant plant material pool (RPM) and 0.91 and 0.94 for the humus pool (HUM) for the intensively monitored and the long-term sites, respectively. Slightly larger errors were detected for the intensively monitored sites together with a bias in the relationship between the RPM pool and particulate organic matter fraction. This bias detected for the intensively monitored sites indicated that the equilibrium assumption for arable agricultural sites, even though under crop cover for at least 50 years, might not be entirely valid. From the relative mean absolute error of $11 \%$ for the HUM pool and $26 \%$ for the RPM pool of the combined data set we conform that the measured fractions can be used to estimate the RothC model pools in arable soils. Given the magnitude of these errors, however, we rather suggest to apply the fractionation approach instead of using an equilibrium assumption for the RothC initialisation of arable sites.
\end{abstract}

keywords: particulate organic matter, inversion, carbon turnover, fractionation 


\section{Introduction}

Against the background of global climate change and for the preservation of soil productivity the quantification of changes in soil carbon is highly relevant. Dynamic models of soil carbon turnover are valuable tools to improve our understanding and to provide reliable predictions of soil organic carbon response to changes in climate or management (Smith et al., 2002; Schmidt et al., 2011). Basically, such models of soil carbon turnover can be divided into two categories: they either consider soil organic matter as a continuum of compounds of different degradability (e.g. Bruun et al., 2010) or they conceptualize it into discrete pools that release carbon at different rates with different turnover time, e.g. in the Rothamsted carbon model RothC (Coleman and Jenkinson, 2005). RothC defines one inert organic matter pool (IOM) and four active compartments: decomposable plant material (DPM), resistant plant material (RPM), humus (HUM) and carbon stored in the microbial biomass (BIO). No matter how the soil carbon quality is characterised, it remains a challenge to link measured fractions with soil $\mathrm{C}$ pools which are indirectly derived from the evolution of carbon stocks and carbon fluxes using simulation models (Smith et al., 2002; Olk and Gregorich, 2006).

Apart from fractionation-based estimation of initial pool sizes, the assumption of TOC equilibrium is by far the common model approach (Foreid et al., 2012). Here, a spin-up run is performed to derive initial pools for which the available climatic input data is looped until the simulated TOC content is stable for a given amount of carbon inputs. This amount of carbon inputs could be adjusted, or inversely estimated, in such a way that the simulated TOC stocks match the measurement.

The establishment of a link between measurements and simulation of soil carbon pools is required for the initial parameterisation and validation of carbon turnover models. Due to the sensitivity of the model simulations to the initial parameters used (Wutzler and Reichstein, 2007; Ludwig et al., 2010; Scharnagl et al., 2010; Hashimoto et al., 2011; Foreid et al., 2012; Weihermüller et al., 2013; Nemo et al., 2016), an initial parameterisation method based on independent measurements is highly desirable (Skjemstad et al., 2004). However, models with a discrete pool structure are inherently conceptual with turnover rates assigned to each pool whilst experimental procedures designed to split the soil total organic carbon (TOC) into separate fractions are operationally defined (Olk and Gregorich, 2006). Consequently, an understanding of the relationship between physically defined soil $\mathrm{C}$ pools and the conceptual pools in soil $\mathrm{C}$ models is important to ensure they accurately represent the key processes 
controlling soil $\mathrm{C}$ dynamics. Several attempts have been made to define fractionation procedures, which correspond to the conceptual model pools of RothC. Balesdent (1996), for instance, applied a suite of chemical and physical fractionation procedures and identified a good correspondence between the organic matter in the particle-size fraction $>50 \mu \mathrm{m}$ and the RPM pool of RothC. The author further detected correspondence between the organic carbon in the particle-size fraction $<50 \mu \mathrm{m}$ and sum of the HUM, BIO and IOM pools. Skjemstad et al. (2004) related the particulate organic matter (POM) fraction $>53 \mu \mathrm{m}$ to the RPM pool, the fraction $<53 \mu \mathrm{m}$ to the HUM pool and the inert pool IOM was related to charcoal carbon isolated by photo-oxidation. Based on data from two long-term field experiments they found good agreement between fractions and pools after calibrating the RPM turnover rate. Zimmermann et al. (2007) separated a fraction $>63 \mu \mathrm{m}$, which was further separated into two classes of light and heavy density, dissolved organic carbon and resistant carbon by $\mathrm{NaOCl}$ oxidation. They found good correlation between the model pools, which were derived assuming dynamic equilibrium, and experimentally determined fractions for a comprehensive data set of arable, grassland and alpine sites in Switzerland. Based on the same fractionation approach Leifeld et al. (2009) reported that both, spin-up equilibrium or measured fractions initialisation, allowed to simulate satisfactorily the TOC dynamic of a 27-year field experiment in Switzerland. Dondini et al. (2009) also essentially followed the approach suggested by Zimmermann et al. (2007) and found that the RothC pools matched the measured fractions within one standard error for a long-term conversion trial in Ireland. Xu et al. (2011) also applied the approach of Zimmermann et al. (2007) to eight Irish grassland sites and detected good correlation between the HUM pool and the measured fractions, however the correlation between RPM and the respective fraction was poor. They further recommended that the fractionation result should differ by less than $10 \%$ from the RPM pool for accurate model initialisation. Weihermüller et al. (2013) essentially followed the fractionation approach suggested by Skjemstad et al. (2004) and determined a correlation coefficient of 0.84 between the RPM pool and the fractionation result for a data set comprising 39 sites located in lower Saxony, Germany. Finally, Nemo et al. (2016) investigated the effects of three initialization procedures on the model performance and concluded that the fractionation-based model initialisation of the RPM pool was more efficient than the equilibrium-based initialisation approaches. Notably, almost all of the above-mentioned studies relate fractions to pools originating from model runs based on an equilibrium spin-up approach. Only the study of Skjemstad et al. (2004), covering a relatively 
short span of 18 years, related fractions to pools estimated by dynamic (non-equilibrium) model runs, which may be more appropriate than equilibrium models for arable sites.

On the other hand, repeated inventories suggest that in recent decades losses of carbon have occurred from arable soils, e.g. Bellamy et al. (2005). Several studies reported that arable soils are not necessarily in TOC steady state equilibrium. E.g. Steinmann et al. (2016a) report temporal trends in the arable topsoil TOC concentrations of North Rhine-Westphalia, Germany, between 1979 and 2015 that were related to changes in land use and management practice. In a more detailed study, Steinmann et al. (2016b) detected positive changes in the humus management for the south-western part of North Rhine-Westphalia as a consequence of the implementation of environmental minimum standards within the framework of the European agricultural reform (Cross Compliance) in 2006. Nemo et al. (2016) also conclude that a TOC steady state assumption may not be valid for arable soils.

Thus, our objectives were to elucidate: (i) whether and to what degree the relations between fractions and RothC model pools reported in literature are valid for dynamic (nonequilibrium) situations, as well as (ii) to quantify how the relation between fractions and model pools differs between equilibrium situations and dynamic long-term experiments.

\section{Material and Methods}

In order to answer the questions outlined above, RothC was applied to 54 intensively monitored sites under long-term arable cropping, for which we assume equilibrium state. Further, RothC was applied to 5 long-term experiments with repeated sampling, resulting in 35 data pairs of fractions and pools. To ensure consistency, a single fractionation procedure was applied to the samples of the intensive monitoring sites and the archived sample material of the long-term experiments.

\subsection{Experimental sites}

The 54 intensive monitoring (IM) sites are all located in the federal state of North RhineWestphalia, Germany, which covers an area of about $34000 \mathrm{~km}^{2}$. All sites are privately owned and have been used as arable land under conventional agricultural practice for at least the last 50 years. The total soil organic carbon (TOC) stocks in the plough layer varied 
between 32 and $127 \mathrm{t} \mathrm{ha}^{-1}$. Also the textural properties cover a broad spectrum of silty-loamy to sandy soils, only three sites have clay contents higher than $25 \%$ (Fig. 1).

Four out of the five long-term experiments (LE) are also located in North Rhine-Westphalia, Germany. The Hoosfield experiment was established in 1852 at Rothamsted (Harpenden, UK) to examine the effects of different mineral fertilisers and organic manures on the yield of continuous spring barley (Aldana-Jague et al., 2016). It is one of several "Classical" field experiments established at Rothamsted in the middle of the nineteenth century which continue today (Anon, 2006; Storkey et al, 2016). Dried plant and soil samples collected from these experiments since the mid 1800's are stored in the Rothamsted Sample Archive. Both fresh and archived soils from selected treatments on Hoosfield were used to provide a comprehensive time series (1882-2012) in this study. Treatments studied included an unmanured plot which received mineral $\mathrm{N}$ only since 1968 plus two additional plots which received farmyard manure (FYM) plus mineral N since 1852 and 2001 respecively. Fresh soils (0-29 $\mathrm{cm}$ or less, depending on the treatment) were collected by hand, using a $2 \mathrm{~cm}$ diameter gouge auger, from 10-15 positions within each plot. The cores obtained were bulked to give a singe sample of about $800 \mathrm{~g}$. In addition, about $70 \mathrm{~g}$ of air-dry soil $(0-23 \mathrm{~cm})$, collected from corresponding plots on several occasions between 1852 and 2008, were taken from the sample archive. Treatments selected within each of the other long-term experiments include plots which have undergone changes in soil $\mathrm{C}$ as a result of the different $\mathrm{C}$ inputs and managements imposed. They include a conventional treatment (NPK), representing common agricultural management practices, including the application of $\mathrm{N}, \mathrm{P}$ and $\mathrm{K}$ as mineral fertilizer $(+\mathrm{MF})$ and farmyard manure only $(+\mathrm{FYM})$. Various combinations of mineral and organic amendment are specific to each experimental site, where the total cut of fertilizer and manure application (-MF/-FYM) at the Dikopshof and Dülmen LE, represents the most extreme treatment. The locations as well as the climatic and soil characteristics for each of the LE sites are shown in Table 1. 


\subsection{Soil analyses}

All samples were air-dried and sieved to $<2 \mathrm{~mm}$. Total $\mathrm{C}$ was determined in ball-milled subsamples after dry combustion with an elemental analyser (Fisons NA 2000; ISO 10964). Total soil organic carbon (TOC) was determined as total C minus inorganic carbon (Scheibler method).

The POM fractionation was performed according to Christensen (1992) using ultrasonic dispersion (Amelung and Zech, 1999). After a first and rather weak ultrasonic treatment (60 J $\mathrm{ml}^{-1}$ ) with a probe-type sonicator (Branson Digital Sonifier W-250 D), the coarsest POM fraction POM1 $(250-2000 \mu \mathrm{m})$ was determined by wet sieving. The filtered remnant was treated for a second time with ultrasound at $240 \mathrm{~J} \mathrm{ml}^{-1}$. In the next step the medium POM fraction POM2 (53-250 $\mu \mathrm{m})$ and the fine POM fraction POM3 $(20-53 \mu \mathrm{m})$ were determined by sieving. In the last step, the soil fractions were oven-dried at $40^{\circ} \mathrm{C}$ and gravimetric organic carbon contents of each fraction were measured as described above. The concentration of mineral-bound organic carbon $(<20 \mu \mathrm{m}$, nonPOM) was calculated by substracting the $\mathrm{C}$ concentrations of the POM fractions from that of bulk soil organic carbon (SOC). This calculation includes potential $\mathrm{C}$ losses during fractionation; however, as outlined by Amelung et al. (1999) for grassland soils these losses accounted for only $6 \%$ of total SOC present, on average. Arable sites usually exhibited lower SOC losses upon fractionation (Lobe et al., 2001).

The procedure desrcribed above is essentially identical to the procedure proposed by Skjemstad et al. (2004), except for the dispersion method where Skjemstad et al. (2004) used hexametaphosphate instead of ultrasound.

Soil texture was analyzed according to Köhn by wet sieving and sedimentation (ISO 11277, 2009).

\subsection{Model setup}


The German Weather Service DWD provided monthly data on 2-m air temperature, precipitation and grass reference evapotranspiration according to Wendling (1995), which is based on the FAO Penman-Monteith approach, on a $1 \mathrm{~km}^{2}$ grid for the period $1961-2010$. For the model forcing the dataset of the grid cell the IM or the LE site was located in was selected. Weather data (long-term monthly averages) used to run model simultions for comparison with the Hoosfield experimental data were obtained from the Rothamsted weather file (Coleman and Jenkinson, 2005).

We applied the original RothC Version 26.3 (Coleman and Jenkinson, 2005), with standard partitioning and turnover rates. For inversion we coupled the Downhill-Simplex-Algorithm (Nelder and Mead, 1965) to RothC.

\subsubsection{Intensive monitoring sites}

The goal of the model runs performed for the IM sites was to determine the size of each model pool at equilibrium. This was achieved by inverting the model for carbon inputs at each IM site and target was the TOC stock measured in 2010. In other words, the carbon inputs were adjusted in such a way that the model at equilibrium state reproduced the 2010 TOC measurements. In order to ensure equilibrium the 50 years times series (1961-2010) of meteorological boundary conditions was looped 15 times, resulting in an overall model period of 750 years. We assumed that the carbon inputs entered the soil as plant material. Half of the total yearly input was assumed to enter the soil in August as plant residues, 1/6 of the total input was expected to occur in each of the three previous month as root exudates (Kuzyakov and Domanski, 2000). The initial pools were all set to zero, except for IOM. The IOM pool is not an active part of the carbon cycling in RothC (Falloon et al., 2000), thus we followed the approach of Falloon et al. (1998) and estimated the size of the IOM pool in dependence of the TOC content. Topsoil thickness and clay content data at each of the IM sites were available.

\subsubsection{Long-term experiments}

For the dynamic model runs at the LE sites RothC was set up as following. The LE in Dikopshof is based on a fixed crop rotation of sugar beet, winter wheat, winter rye, clover and 
potato. Crop yield was available from 1949 on. The carbon inputs from plant residues were estimated assuming a linear relation between plant residues and measured crop yield. Cropspecific intercept and slope of this linear relation was given by Franko (1997). In order to account for the inputs by root exudates for winter wheat, winter rye and clover another $50 \%$ of the plant residues (Kuzyakov and Domanski, 2000) were added as carbon inputs distributed over the three months before harvest, when the plant residues were expected to enter the soil. For potato and sugar beet another $35 \%$ of the plant residues were assumed to enter the soil as root exudates (Ludwig et al., 2007). This resulted in average carbon inputs from plant residues for the -MF/-FYM, -MF/+FYM , $+\mathrm{MF} /-\mathrm{FYM}$ and +MF/+FYM treatment of $1.18,1.40,1.42$ and $1.56 \mathrm{tha}^{-1} \mathrm{y}^{-1}$, respectively. About $20 \mathrm{t} \mathrm{ha}^{-1}$ of manure were applied as organic fertilizer to two of the four treatments (Table 1) following the harvest of potato, sugar beet or winter rye. Assuming a dry matter content of 25\% (Franko, 1997) and a carbon content of $36 \%$ resulted in a carbon input of $1.8 \mathrm{t} \mathrm{ha}^{-1}$ in three out of five years. A soil cover factor of one was applied in the months between crop emergence and harvest, zero in all other months.

The experimental site in Duelmen was managed with a fixed crop rotation of potato, winter rye and oat. The estimation of the carbon input by plant residues and organic fertilization was performed analogous to the procedure applied to the Dikopshof data. Treatment-specific crop yield was available for the entire simulation period.

For the Poppelsdorf LE a non-uniform crop rotation including broad bean, winter wheat, sugar beet, winter rye, pea and oat was given. Treatment-specific crop yield was available for the 1966-1994 period. The LE in Meckenheim was managed with a rather diverse and nonuniform crop rotation including wheat, rye, sugar beet, winter wheat, maize, clover, winter rye, potato and oat. Crop yield was available for the 1990-2005 period. For Poppelsdorf and Meckenheim the gaps in yield data were filled with the treatment-specific average yield of each crop. Plant residues and organic fertilization was estimated according to the procedure described above for the Dikopshof site. Measured clay content and topsoil thickness is given in Table 1.

In dependence of yield data availability and the first sampling for TOC at Dikopshof, Duelmen, Poppelsdorf and Meckenheim the simulation period started in 1949, 1958, 1948 and 1959, respectively. The gap in meteorological information prior to 1961 was filled with the first years of meteorological data starting in 1961. 
The initial RPM, BIO and HUM pool of the four German LEs were calculated treatmentspecific, assuming equilibrium in dependence of the measured TOC and clay content according to Weihermüller et al. (2013). The IOM pool was estimated following Falloon et al. (1998). The initial DPM pool was set to zero since due to the high turnover of this pool, the amount of DPM in January would be very small and equilibrated very soon after the first carbon inputs (Herbst et al., 2008). TOC measurements were available for Dikopshof and Meckenheim. For Duelmen and Poppelsdorf no initial TOC data was available. For the latter the initial TOC value was inversely estimated, whereas an initial TOC content of $1.6 \%$ mass was assumed for the Duelmen experimental site in 1958.

The model setup of the Hoosfield barley LE essentially followed Jenkinson and Rayner (2006) and Coleman and Jenkinson (2005). In short, the plot without organic fertilization received $1.6 \mathrm{t} \mathrm{Cha}^{-1} \mathrm{y}^{-1}$ as plant residues, whereas the plot with organic fertilization received $2.8 \mathrm{t} \mathrm{ha}^{-1} \mathrm{y}^{-1}$ as plant residues plus $3 \mathrm{t} \mathrm{C} \mathrm{ha}^{-1} \mathrm{y}^{-1}$ from farmyard manure. A section of the plot without fertilization between 1852 and 2000 was fertilized with manure starting in 2001 . Again, 3 t C ha ${ }^{-1} \mathrm{y}^{-1}$ were applied. A soil cover factor of zero was used between August and March of the following year, one in the other months. The pools of three treatments for the Hoosfield plot were all initialised by the same values originating from an equilibrium run with an annual input of $1.7 \mathrm{t} \mathrm{Cha}^{-1} \mathrm{y}^{-1}$ and an IOM pool of $2.7 \mathrm{tha}^{-1}$ (Coleman and Jenkinson, 2005).

In the original RothC version the model is primed to run open pan-evaporation data, which was multiplied internally by 0.75 to give actual evapotranspiration. This scaling factor of 0.75 basically also accounts for the transfer of potential evapotranspiration to actual evapotranspiration. In all model runs for the LE sites this factor, further referred to as $\mathrm{f}_{\mathrm{ET}}$, was inversely estimated. Basic assumption was that treatments with stronger crop cover, characterized by higher biomass and higher yields, will also have an increased transpiration demand. Via the topsoil moisture deficit and the related rate modifying factor this was expected to affect carbon turnover. An increased evapotranspiration would cause less carbon turnover.

In order to show the effect of assuming equilibrium conditions for each sampling of the LE sites additional equilibrium models were set up exactly the way the equilibrium runs for the IM sites (section 2.3.1) were performed. For each single measurement the climatic inputs 
were looped and the carbon inputs were adjusted inversely such that the measured TOC stock was reproduced.

\subsection{Model pools and fractions}

According to Skjemstad et al. (2004) the RothC RPM pool is equivalent to POM larger than $53 \mu \mathrm{m}$. Thus, $\mathrm{f}_{\mathrm{POM}}$ was defined as the sum of POM1 and POM2. The HUM pool was expected to be equivalent to the non-POM fraction of the soil $\mathrm{f}_{\mathrm{HUM}}$ defined as:

$f_{H U M}=T O C-f_{P O M}-P O M 3-I O M$

where IOM was estimated according to Falloon et al. (1998). This represents a simplification, since the DPM and the BIO pool are neglected. However the BIO pool is usually very small, having a ratio of 0.026 to the HUM pool according to Zimmermann et al. (2007), and the amount of DPM carbon is usually even smaller. The DPM and the BIO pool decompose fast, thus simulations are rather insensitive to their initial pool size (Herbst et al., 2008; Leifeld et al., 2009). The RothC pools are defined as carbon stocks, given as $\mathrm{t} \mathrm{ha}^{-1}$. The measured carbon total and fractional concentrations $\left(\mathrm{g} \mathrm{g}^{-1}\right)$ were converted to stocks using site-specific information on topsoil horizon depth $(\mathrm{cm})$ and bulk density $\left(\mathrm{g} \mathrm{cm}^{-3}\right)$. This information was available for the LEs as well as for each of the IM sites.

\subsection{Statistical measures}

Differences between fractionation results and respective model pools were quantified by the mean absolute error MAE, given as the average of the absolute differences between fraction and pool, and the mean error ME, which indicates bias for values $\neq 0$. We also calculated the root mean square error RMSE, given as

$$
R M S E=\sqrt{\frac{\sum_{i=1}^{n}\left(F_{i}-P_{i}\right)^{2}}{n}}
$$


where $F_{i}$ stands for the fractionation result, $P_{i}$ for the model pool and $n$ is the number of fraction vs. pool pairs with index $i$. The RMSE is more sensitive to large deviations than the MAE. The statistical significance of the differences between the mean of the fractions and pools was analysed with unpaired t-tests. Large t-values associated with low error probabilities indicate that the alternative hypothesis, i.e. that the means differ significantly, is valid. Correlations were quantified by the Pearson correlation coefficient $r$, if not specified otherwise. T-values were computed and significance is given in terms of the error probability $p$.

\section{Results}

3.1 Model results long-term experiments

The comparison between TOC measurements and model results for the LEs is shown in Fig. 2. Basically, a good agreement was observed. The root mean square error (RMSE) between model and measurements was $2.1 \mathrm{t} \mathrm{ha}^{-1}$ for the $-\mathrm{MF} /-\mathrm{FYM}, 2.7 \mathrm{tha}^{-1}$ for $-\mathrm{MF} /+\mathrm{FYM}, 2.3 \mathrm{t}$ $\mathrm{ha}^{-1}$ for $+\mathrm{MF} /-\mathrm{FYM}$ and $3.1 \mathrm{tha}^{-1}$ for the $+\mathrm{MF} /+\mathrm{FYM}$ treatment at Dikopshof. For all LEs the differences in the treatments according to the variation of mineral fertilization and organic amendments was reproduced by RothC. For example the $+\mathrm{MF} /+\mathrm{FYM}_{20}$ treatment at Dikopshof showed an almost stable level of TOC. The other three treatments showed a tendency of decreasing TOC over the simulation period, where a small loss was observed for the $-\mathrm{MF} /+\mathrm{FYM}_{20}$ treatment. Bigger losses were detected for two treatments without FYM application. This all was reproduced by the inverted models for the Dikopshof site. The inversion yielded $\mathrm{f}_{\mathrm{ET}}$ estimates of $0.73,0.75,0.79$ and 0.77 for the $-\mathrm{MF} / \mathrm{FYM},-\mathrm{MF} /+\mathrm{FYM}$, $+\mathrm{MF} /-\mathrm{FYM}$ and $+\mathrm{MF} /+\mathrm{FYM}$ treatment, respectively. All estimates were quite close to the $\mathrm{f}_{\mathrm{ET}}$ default value of 0.75 . The respective annual average evapotranspiration was 597, 612, 640 and $629 \mathrm{~mm} \mathrm{y}^{-1}$, which appears quite reasonable from a hydrological point of view. This supports the assumption of a higher evapotranspiration for stronger crop cover and the ranking of the treatments according to the carbon inputs reported in section 2.3.2.

The massive increase in TOC stocks for the Hoosfield $+\mathrm{N} /+\mathrm{FYM}_{1852}$ treatment as well as the small decrease for the $+\mathrm{N} /-\mathrm{FYM}$ was reproduced by the model. The respective $\mathrm{f}_{\mathrm{ET}}$ estimates were 0.83 and 0.62 . For the $+\mathrm{N} /+\mathrm{FYM}_{2001}$ a $\mathrm{f}_{\mathrm{ET}}$ value of 0.77 was estimated. This again supports the assumption of a higher evapotranspiration for stronger crop cover, however the deviation from the default value was larger than for Dikopshof. Nevertheless, also the 
discrepancy in the yields and thus probably also the discrepancies in the standing biomass were larger between the treatments at the Hoosfield experiment than at Dikopshof. The model RMSE was $4.3 \mathrm{tha}^{-1}$ for the $+\mathrm{N} /+\mathrm{FYM}_{1852}, 2.0 \mathrm{tha}^{-1}$ for the $+\mathrm{N} /-\mathrm{FYM}$ and $4.2 \mathrm{tha}^{-1}$ for the $+\mathrm{N} /+\mathrm{FYM}_{2001}$ treatment.

Basically, also the TOC stocks of the treatments at the Meckenheim LE were nicely reproduced by RothC. The 1985 TOC value of the +MF/-FYM was underestimated by the model, however the TOC measurement shows a rather unexpected high value of $52.5 \mathrm{t} \mathrm{ha}^{-1}$, almost as high as the TOC value of $53.3 \mathrm{tha}^{-1}$ measured for the $+\mathrm{MF} /+\mathrm{FYM}_{20}$ treatment. The RMSE was $2.9 \mathrm{t} \mathrm{ha}^{-1}$ for the $+\mathrm{MF} /+\mathrm{FYM}_{40}, 4.0 \mathrm{t} \mathrm{ha}^{-1}$ for the $+\mathrm{MF} /+\mathrm{FYM}_{20}$ and $5.1 \mathrm{tha}^{-1}$ for the $+\mathrm{MF} /-\mathrm{FYM}$ treatment.

The data of the Poppelsdorf LE only comprises two TOC measurements, and with a RMSE of $2.9 \mathrm{t} \mathrm{ha}^{-1}$ model results deviate just slightly from that. For the model runs at the Poppelsdorf LE the initial TOC value was estimated in the inversion process, however due to the extended period between the model start and the first TOC measurement and carbon fractionation results ( $\sim 50$ years) the influence of the initial values on the pools estimated at the time of sampling can be expected to be rather small.

A rather high scatter was observed for the TOC measurements carried out for the Duelmen LE. This scatter induces rather large RMSEs of $5.4 \mathrm{t} \mathrm{ha}^{-1}$ for the $-\mathrm{MF} /-\mathrm{FYM}, 5.1 \mathrm{tha}^{-1}$ for the $+\mathrm{MF} /-\mathrm{FYM}$ and $6.5 \mathrm{tha}^{-1}$ for the $-\mathrm{MF} /+\mathrm{FYM}$ treatment. However, parts of this error are probably related to a less representative sampling for the TOC measurements. It should be noted that the site in Duelmen was the only one, which exhibited a stagnic moisture regime in the subsoil (Stagnic Cambisol).

In summary, the mean estimated TOC stock across all sites and sampling dates differed to the respective mean of all measurements by $1.0 \mathrm{t} \mathrm{ha}^{-1}$. Also the related standard deviation was very similar (Table 2). The Pearson correlation coefficient between TOC measurement and model result across all sites and sampling dates was $0.98(\mathrm{p}<0.0005)$.

\subsection{Model results intensive monitoring sites}

Figure 3 shows the pools estimated from the RothC model inversions, based on the TOC measurements at the $54 \mathrm{IM}$ sites assuming equilibrium. The inversely adjusted mean total carbon input across all IM sites was $4.6 \mathrm{tha}^{-1} \mathrm{y}^{-1}$, with a standard deviation of $1.8 \mathrm{tha}^{-1} \mathrm{y}^{-1}$. 
Inherently, the measured TOC values were exactly reproduced and the estimated pools expose a broad variation. The largest pool was in any case the HUM pool, followed by RPM and IOM. The mean HUM/TOC ratio was 0.74 associated with a standard deviation of 0.015 , whereas the mean RPM/TOC ratio was $0.15 \pm 0.014$. The BIO and the DPM pool were very small in relation to the other pools. The ratio between the two biggest active pools, RPM/HUM, relates the labile to the recalcitrant carbon and had a mean value of 0.20 with a standard deviation of 0.023 across all IM sites.

\subsection{Pools and fractions}

In a first step we compared the statistical characteristics in terms of the mean and the standard deviation of the RothC pools to the statistical characteristics of the corresponding fractions. The $f_{P O M}$ and the RPM mean values of the LE data set were very similar, however the standard deviation of the RPM pool was $0.7 \mathrm{t} \mathrm{ha}^{-1}$ higher than for the $\mathrm{f}_{\mathrm{POM}}$ fraction (Table 2). Also the HUM pool showed a $1.2 \mathrm{t} \mathrm{ha}^{-1}$ higher standard deviation than the $\mathrm{f}_{\mathrm{HUM}}$ fraction. Here, the mean of the HUM pool was $1.8 \mathrm{t} \mathrm{ha}^{-1}$ higher than the corresponding mean of $\mathrm{f}_{\mathrm{HUM}}$. Hence, overall the fractions corresponded quite well to the modelled pool sizes of the LE. For the intensive monitoring sites the mean of $\mathrm{f}_{\mathrm{POM}}$ and RPM differed by just $0.7 \mathrm{t} \mathrm{ha}^{-1}$, but the standard deviation of the RPM pool was $0.9 \mathrm{t} \mathrm{ha}^{-1}$ lower than for the $\mathrm{f}_{\mathrm{POM}}$ fraction. Between the mean $\mathrm{f}_{\mathrm{HUM}}$ fraction and the HUM pool of the IM sites the biggest difference of $4.3 \mathrm{tha}^{-1}$ was observed. The related standard deviation was $1.7 \mathrm{t} \mathrm{ha}^{-1}$ lower for the $\mathrm{f}_{\mathrm{HUM}}$ fraction than for the HUM pool.

Table 2 also summarizes the results of the unpaired t-test between the pools and the corresponding fractions. The t-values close to zero and the high error probabilities detected for the LE sites clearly indicate that the alternative hypothesis, i.e. that the mean of the fraction and the mean of the model pool differ significantly, has to be rejected. This basically also holds for the means of the $f_{\mathrm{POM}}$ fraction and the RPM pool of the IM sites. Only the $\mathrm{f}_{\mathrm{HUM}}$ and the HUM pool means of the IM sites tended to differ significantly at an error probability of $7 \%$.

In a next step the Pearson correlation coefficients and the errors of the fraction vs. pool data pairs were computed. The lowest correlation of $0.73(\mathrm{p}<0.0005)$ was detected for the $\mathrm{f}_{\mathrm{POM}} / \mathrm{RPM}$ relation of the IM sites. For the LE sites the $\mathrm{f}_{\mathrm{POM}} / \mathrm{RPM}$ correlation was slightly higher (Table 3 ). The $\mathrm{f}_{\mathrm{HUM}} / \mathrm{HUM}$ correlation in contrast exceeded Pearson coefficients of 0.91 
$(\mathrm{p}<0.0005)$ for both, LE and IM sites. Also the mean absolute errors as well as the root mean square errors were in an acceptable range, with the errors being always higher for the $\mathrm{f}_{\mathrm{HUM}} / \mathrm{HUM}$ relation, which reflects higher absolute values of the HUM pool in comparison to RPM. The mean errors, as an indicator for bias, were negative for the $f_{\mathrm{HUM}} / \mathrm{HUM}$ relation, confirming that the $\mathrm{f}_{\mathrm{HUM}}$ fraction tended to be on average slightly smaller than the HUM pool (see Table 2).

Figure 4 shows 1:1 plots of measurements and model pools for the LE sites. The top panel again illustrates the excellent agreement between TOC measurements and model results. The regression intercept was close to zero and the slope was close to one, which basically indicates that systematic errors are not present. Despite an overall $\mathrm{R}^{2}$ of $0.97(\mathrm{p}<0.0005)$, however, single model results deviated from the TOC measurements. The largest deviation referred to the Hoosfield sampling of the $+\mathrm{N} /+\mathrm{FYM}_{2001}$ treatment in 2000 . We measured a TOC stock of $35 \mathrm{t} \mathrm{ha}^{-1}$, whereas the model result was $26 \mathrm{t} \mathrm{ha}^{-1}$. This could probably be explained by elevated $\mathrm{P}$ and $\mathrm{K}$ levels of this plot, in relation to the other two Hoosfield plots, measured before FYM application in 2001. The higher nutrient level would have slightly increased biomass production and thus also the $\mathrm{C}$ inputs via crop residues at the $+\mathrm{N} /+\mathrm{FYM}_{2001}$ plot. The regression slope in the $\mathrm{f}_{\mathrm{POM}}$ vs. RPM plot indicates a very small tendency to underestimate the RPM pool by $f_{\mathrm{POM}}$ measurements for larger $\mathrm{f}_{\mathrm{POM}}$ values (Fig. 4, middle). The scatter was clearly larger than observed for TOC. As indicated by the coefficient of determination less scatter was detected for the $\mathrm{f}_{\mathrm{HUM}} / \mathrm{HUM}$ relation. The regression intercept and slope in the $f_{\text {HUM }}$ vs. HUM plot indicates a $C$ offset of about minus $1 \mathrm{t} \mathrm{ha}^{-1}$ for the $f_{\text {HUM }}$ fraction in relation to the HUM pool over the entire range between 17 and $64 \mathrm{t} \mathrm{ha}^{-1}$ (Fig. 4, bottom).

In contrast to the LE sites, a clear systematic deviation was observed for the $\mathrm{f}_{\mathrm{POM}} / \mathrm{RPM}$ relation of the IM sites (Fig. 5, top). The regression line shows that the $f_{\mathrm{POM}}$ results were on average higher than the RPM pool for values larger than $9 \mathrm{t} \mathrm{ha}^{-1}$. Lower values of $\mathrm{f}_{\mathrm{POM}}$ tended to underestimate the RPM pool. The $\mathrm{f}_{\mathrm{POM}} / \mathrm{RPM}$ relation of the IM sites showed also a larger scattering than for the LE sites. Like for LE sites, a negative offset was detected for the $f_{H U M}$ fraction in relation to the HUM pool of the IM sites (Fig. 5 bottom). However, the average offset of minus $3.3 \mathrm{t} \mathrm{ha}^{-1}$ was larger, and also the coefficient of determination of 0.84 $(p<0.0005)$ was slightly smaller than the corresponding value of $0.89(p<0.0005)$ determined for the LE sites. 
Figure 6 shows the relation between the RPM pool and the $f_{P O M}$ fraction of the LE sites when equilibrium was assumed. Here, we used the LE sites data and handled it according to the procedure used to model the IM sites under the equilibrium assumption. In contrast to the results of the dynamic model runs for the LE sites (Fig. 4) the RPM/ $f_{\mathrm{POM}}$ relation assuming equilibrium was also biased. This is clearly indicated by a regression coefficient of 0.49 and a regressions intercept of $3 \mathrm{tha}^{-1}$. For values larger than about $6 \mathrm{tha}^{-1} \mathrm{f}_{\mathrm{POM}}$ results were on average higher than the RPM pool, which was quite similar to what we observed for the IM sites.

We also combined both data sets, which basically resulted in a smaller bias in the fPOM/RPM relation than for the IM sites only. The regression coefficient was 0.72 and the regression intercept was $2.23 \mathrm{t} \mathrm{ha}^{-1}$. The coefficient of determination of the combined data set for the $\mathrm{RPM} / \mathrm{f}_{\mathrm{POM}}$ relation was $0.59(\mathrm{p}<0.0005)$. Also, the small negative offset observed for the $\mathrm{F}_{\text {HUM }}$ fractionation result in relation to the HUM pool was present in the combined data set, as indicated by a regression intercept of $1.35 \mathrm{t} \mathrm{ha}^{-1}$. The regression coefficient was 1.05 and the coefficient of determination was $0.87(\mathrm{p}<0.0005)$.

\section{Discussion}

The model runs reproduced the measured TOC stocks at the LE sites reasonable well, as indicated by the coefficient of determination and the RMSE being similar to those found earlier by e.g. Smith et al. (1997), Ludwig et al. (2010) or Taghizadeh-Toosi et al. (2014). The reproduction of the measured TOC values of the LE sites is quite relevant for the subsequent comparison of fractions and pools. Any error in the modelling of TOC will propagate into the estimated size of the pools, which in turn would of course affect the relation detected between the fractions and the pools.

For both, the LE and IM sites, we found a better agreement between the modelled and experimental data for the HUM pool than for the RPM pool, which is in line with observations by Xu et al. (2011) and Zimmermann et al. (2007). The absolute magnitude of the errors was smaller for the $f_{\mathrm{POM}} / \mathrm{RPM}$ relation (Table 2), however when related to the pool size, the $\mathrm{f}_{\mathrm{HUM}} / \mathrm{HUM}$ errors were only half of those observed for RPM. The MAE in relation to the pool size for $\mathrm{f}_{\mathrm{POM}} / \mathrm{RPM}$ corresponded to values of $24 \%$ for the IM and $26 \%$ for the LE sites, whereas the respective values for fHUM/HUM were only 11 and $10 \%$ for IM and LE sites, respectively. This is also expressed by the Pearson correlation coefficients, which were 
always higher for the $\mathrm{f}_{\mathrm{HUM}} / \mathrm{HUM}$ relation (Table 2). The rank correlation coefficients of 0.76 and 0.99 determined by Zimmermann et al. (2007) for the RPM and HUM pool, respectively, correspond well to the respective rank correlations of 0.78 and $0.93(p<0.0005)$ determined in our study for the combined data set. The overall good agreement between pools and fractions, even though empirical in nature, could be explained by the mechanisms of SOC stabilization (Poepleau et al., 2013). Such an explanation is based on the assumption that localisation and physical protection of soil carbon resulting from aggregation and adsorption on mineral surfaces reduces decomposability. After isolating particle-size fractions, characterized by different degrees of aggregation and specific surface area, Balesdent (1996) observed that carbon turnover rates decreased with decreasing particle size. The good correspondence particularly of the RPM pool and the fPOM fraction could be mainly attributed to a well-chosen POM particle size threshold by Skjemstad et al. (2004) that allows to isolate a compartment mainly containing plant structural material.

The bias observed particularly for the $\mathrm{f}_{\mathrm{POM}} / \mathrm{RPM}$ relation of the IM sites was also observed by Zimmermann et al. (2007). They applied the same methodology as we did here, i.e. they inverted the model for recent TOC measurements and estimated the carbon inputs required to meet the equilibrium. However, the bias they observed was in the opposite direction. Their fractionation results revealed, on average, lower values than for the RPM model pool, whereas we found larger values for the fractionated $f_{\mathrm{POM}}$ stocks by up to $9 \mathrm{t} \mathrm{Cha}{ }^{-1}$. This might be explained by a slightly different fractionation procedure, by the fraction to pool conversion method and also by methodological issues regarding the reproducibility of the fractionation itself (Poepleau et al., 2013). Weihermüller et al. (2013) also report a bias in the $f_{P O M} / R P M$ relation, like in our study, the fractionation-based result was higher than the equilibrium RPM pool; these authors applied basically the same physical fractionation procedure and the same fraction to pool conversion that was applied in this study. It thus seems reasonable to assume that the bias between modelled and fractionated data is related to the specification of the fractionation procedure and the fraction to pool conversion strategy. This bias could be corrected for in a simple way, but the correction would very likely only be valid for this data set.

In contrast to the IM sites, no bias was observed in the $f_{\mathrm{POM}} / \mathrm{RPM}$ or the $\mathrm{f}_{\mathrm{HUM}} / \mathrm{HUM}$ relation for the LE sites (see Fig. 4). This was quite surprising, since for both data sets the same fractionation procedure and the same model was used. The only difference was that we did 
not assume steady-state equilibrium for the TOC stocks at the LE sites. This might be explained by the fact that the soils of the IM data set were actually not in carbon turnover equilibrium, even though the sites were explicitly chosen since they were under agricultural practice for at least 50 years. Experimental evidence exists indicating that it takes more than 50 years to reach TOC equilibrium, even under continuous crop regime (Odell et al., 1984). This is also corroborated by model results indicating that soils, which were disturbed centuries ago, are still in a transient state since the slowest pool would still accumulate carbon (Wutzler and Reichstein, 2007). The equilibrium assumption may not hold true particularly for disturbed agricultural sites (Nemo et al., 2016). Over the last decades the agricultural practice substantially evolved in terms of the crop rotation, in terms of crop yield, and thus probably also the amount of plant residues incorporated after harvest, in terms of timing and amount of organic fertilizer application and also in terms of tillage practice. Due to the permanent change of all these factors over decades a strict TOC equilibrium in agricultural topsoils may be prohibited. Steinmann et al. (2016a) reported that the arable topsoils in the federal state of North Rhine-Westphalia are not in equilibrium state. They observed a continuous decrease of SOC content between 1990 and 2015. In a detailed study of the Cologne-Bonn region Steinmann et al. (2016b) found that SOC losses occurred even though the farm-level humus balances had increased positively from $20 \mathrm{~kg} \mathrm{C} \mathrm{ha} \mathrm{y^{-1 }}$ (2003-2005) to

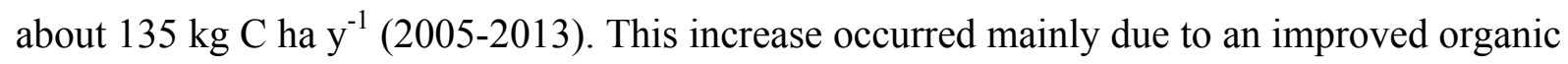
fertilization and intercropping, which makes increased carbon inputs very likely for the entire North Rhine-Westphalia region (Steinmann et al., 2016b) prior to the sampling of the IM sites in 2010. When the carbon inputs increased prior to the sampling in 2010, the $f_{\mathrm{POM}}$ fraction would be expected to be larger than the RPM pool estimated for TOC equilibrium state, which is in line with the RPM/ $\mathrm{f}_{\mathrm{POM}}$ relation we observed for the IM sites in North Rhine-Westphalia. This bias observed for the IM sites could thus be explained increased carbon inputs, which in turn increased the $\mathrm{f}_{\mathrm{POM}}$ fraction.

In case the data of the LEs was handled similarly to the IM data by setting up equilibrium models a bias, similar to the one observed for the IM sites, was detected in the RPM/ $f_{\mathrm{POM}}$ relation. This bias also indicates that the IM sites are not in a full equilibrium state. And in this case the use of the fractionation data as the initial model pools would probably be more appropriate than deriving the initial pools from an equilibrium assumption. The bias observed for the $\mathrm{RPM} / \mathrm{f}_{\mathrm{POM}}$ relation of the LE sites assuming equilibrium is even stronger than observed for the IM sites since the difference of the regression coefficient to 1 is even larger. 
This indicates that the LE sites are on average further away from an equilibrium state than the IM sites, which is plausible as the LEs include treatments for which the carbon inputs were perturbed rather extremely, like e.g. the Hoosfield $+\mathrm{MF} /+\mathrm{FYM}_{1852}$ treatment or the Meckenheim $+\mathrm{MF} /+\mathrm{FYM}_{40}$ treatment.

As an example, Fig. 7 shows the temporal evolution of the fPOM and the fHUM fraction as well as the respective model pools of the three Hoosfield treatments. Basically, the fractionation results are close to the model pools and could probably be used as a proxy for the model pools or for initialisation. Yet, for the $+\mathrm{N} /+\mathrm{FYM}_{1852}$ and the $+\mathrm{N} /+\mathrm{FYM}_{2000}$ treatments in relation to the model a delayed increase of the fPOM fraction was observed. An option would be to adjust the RPM turnover rate as suggested by Skjemstad et al. (2004). It would however remain questionable whether this adjustment would be valid for this data set only.

In section 3.2 we reported that for the equilibrium runs at the IM sites a RPM/TOC ratio of $15 \%$ and a HUM/TOC ratio of $74 \%$, both associated with a very low variance, were detected. This could be explained by the RothC pool structure and the partitioning of carbon fluxes between the pools. As shown by Weihermüller et al. (2013), due to the RothC model formulation these equilibrium RPM/TOC and HUM/TOC ratios are basically independent of the carbon inputs and also independent of the meteorological forcing. The topsoil clay content affects the partitioning and thus also the resulting equilibrium RPM/TOC and HUM/TOC ratios. The rather small standard deviation observed for the ratios is a result of the rather small standard deviation of 7.9 mass \% in the clay contents, linked to a mean clay content of 10.9 mass $\%$, of the IM data set. Our findings (see above) correspond well to the RPM/TOC ratio of $16 \%$ and the HUM/TOC ratio of $80 \%$ detected by Xu et al. (2011).

\section{Conclusions}

From the difference in the bias and the strength of the correspondence between pools and fractions between LE and IM sites we conclude that the assumption of carbon turnover equilibrium might not be valid for sites, which are under agricultural use for at least 50 years.

The correlations and the relative mean absolute errors of about $11 \%$ for HUM and $26 \%$ for RPM indicate that basically the fractionation can be used to estimate the RothC pools. This represents an option to validate and initialize RothC model runs with independent 
measurements. For large-scale applications the accuracy of the fractionation-based pool estimates is probably sufficient. For detailed investigations at long-term experimental sites the accuracy, particularly of the RPM pool, should be improved. Further research is required to correct for the bias in the relation between the POM fractionation and the RPM pool.

\section{Acknowledgements}

The Rothamsted Long-term Experiments National Capability (LTE-NCG) is supported by the UK Biotechnology and Biological Sciences Research Council (BBS/E/C/00005189) and the Lawes Agricultural Trust. Access to the Rothamsted long-term experiments and additional financial support via the transnational work-package of the EU ExpeER project (FP7 INFRA I3 project; contract no. 262060) is gratefully acknowledged. Further, we thank Heidelore Turau (DWD, Abteilung Klima- und Umweltberatung) for the quick and straightforward provision of the NRW climate data. We thank Hubert Hüging for providing the Dikopshof data. 


\section{References}

Aldana-Jague, E., Heckrath, G., Macdonald, A., van Wesemael, B., Van Oost, K., 2016. UAS-based soil carbon mapping using VIS-NIR (480-1000 nm) multi-spectral imaging: Potential and limitations. Geoderma 275, 55-66.

Amelung, W., Zech., W. 1999. Minimisation of organic matter disruption during particle-size fractionation of grassland epipedons. Geoderma 92, 73-85. doi: 10.1016/S00167061(99)00023-3

Anon. 2006. Rothamsted Long-term Experiments: Guide to the Classicals and other Longterm Experiments, Datasets and Sample Archive (www.rothamsted.ac.uk). Lawes Agricultural Trust Co. Ltd, 52 pp.

Balesdent, J., 1996. The significance of organic separates to carbon dynamics and its modelling in some cultivated soils. European Journal of Soil Science 47, 485-493.

Bellamy, P.H., Loveland, P.J., Bradley, I., Lark, R.M., Kirk, G.J.D., 2005. Carbon losses from all soils across England and Wales 1978-2003. Nature 437/8. doi:10.1038/nature04038

Bruun, S., Agren, G.I., Christensen, B.T., Jensen, L.S., 2010. Measuring and modelling continuous quality distributions of soil organic matter. Biogeosciences 7, 27-41.

Christensen, B.T., 1992. Physical fractionation of soil and organic matter in primary particle size and density separates. Advances in Soil Science 20, 1-90.

Coleman, K., Jenkinson, D.S., 2005. RothC-26.3. A Model for Turnover of Carbon in Soil, Model Description and Windows Users Guide. IACR-Rothamsted, Harpenden, 45 pp. http://www.rothamsted.bbsrc.ac.uk/aen/carbon/rothc.htm.

Dondini, M., Hastings, A., Saiz, G., Jones, M.B., Smith, P., 2009. The potential of Miscanthus to sequester carbon in soils: comparing field measurements in Carlow, Ireland to model predictions. GCB Bioenergy 1, 413-425.

Falloon, P., Smith, P., Coleman, K., Marshall, S., 1998. Estimating the size of the inert organic matter pool from total soil organic carbon content for use in the Rothamsted carbon model. Soil Biology \& Biochemistry 30, 1207-1211. 
Falloon, P., Smith, P., Coleman, K., Marshall, S., 2000. How important is inert organic matter for predictive soil carbon modelling using the Rothamsted carbon model? Soil Biology \& Biochemistry 32,433-436.

Foereid, B., Bellamy, P.H., Holden, A., Kirk, G.J.D., 2012. On the initialization of soil carbon models and its effects on model predictions for England and Wales. European Journal of Soil Science 63, 32-41. doi: 10.1111/j.1365-2389.2011.01407.x

Franko, U. 1997. Modellierung des Umsatzes der organischen Bodensubstanz. Archiv für Acker- und Pflanzenbau und Bodenkunde 41: 527-547.

Hashimoto, S., Wattenbach, M., Smith, P., 2011. A new scheme for initializing process-based ecosystem models by scaling soil carbon pools. Ecological Modelling 222, 3598-3602.

Herbst, M., Hellebrand, H.J., Bauer, J., Huisman, J.A., Simunek, J., Weihermüller, L., Graf, A., Vanderborght, J., Vereecken, H., 2008. Multiyear heterotrophic soil respiration: evaluation of a coupled $\mathrm{CO}_{2}$ transport and carbon turnover model. Ecological Modelling $214,271-283$.

ISO 11277, 2009. Soil quality - Determination of particle size distribution in mineral soil material - Method by sieving and sedimentation. Beuth-Verlag, Berlin. 34 pp.

Jenkinson, D.S., Rayner, J.H., 2006. The turnover of soil organic matter in some of the Rothamsted classical experiments. Soil Sci. 123, 298-305.

Kuzyakov, Y., Domanski, G., 2000. Carbon input by plants into the soil - Review. Journal of Plant Nutrition and Soil Science 163, 421-431.

Leifeld, J., Reiser, R., Oberholzer, H.-R., 2009. Consequences of conventional versus organic farming on soil carbon: results from a 27-year field experiment. Agronomy Journal 101, 1204-1218.

Lobe, I., Amelung, W., Du Preez, C. C., 2001. Losses of carbon and nitrogen with prolonged arable cropping from sandy soils of the South African Highveld. Eur. J. Soil Sci. 52, 93101.

Ludwig, B., Schulze, E., Rethmeyer, J., Merbach, I., Flessa, H. 2007. Predictive modelling of $\mathrm{C}$ dynamics in the long-term fertilization experiment at Bad Lauchstädt with the Rothamsted Carbon Model. European Journal of Soil Science 58, 1155-1163. 
Ludwig, B., Hu, K., Niu, L., Liu, X., 2010. Modelling the dynamics of organic carbon in fertilization and tillage eperiments in the North China Plain using the Rothamsted Carbon Model - initialization and calculation of C inputs. Plant Soil 332, 193-206.

Nelder, J.A., Mead, R.A., 1965. A simplex method for function minimization. Comput. J. 7, 308-313.

Nemo, Klumpp, K., Coleman, K., Dondini, M., Goulding, K., Hastings, A., Jones, M.B., Leifeld, J., Osborne, B., Saunders, M., Scott, T., Teh, Y.A., Smith, P., 2016. Soil organic carbon (SOC) equilibrium and model initialisation methods: an application to the Rothamsted carbon (RothC) model. Environmental Model Assessment, doi: $10.1007 / \mathrm{s} 10666-016-9536-0$

Odell, R.T., Melsted, S.W., Walker, W.W., 1984. Changes in organic carbon and nitrogen of Morrow plot soils under different treatments, 1904-1973. Soil Science 137, 160-171.

Olk, D.C., Gregorich, E.G., 2006. Overview of the symposium proceedings „Meaningful pools in determining soil carbon and nitrogen dynamics“. Soil Sci. Soc. Am. J. 70, 967974.

Poepleau, C., Don, A., Dondini, M., Leifeld, J., Nemo, R., Schumacher, J., Senapati, N., Wiesmeier, M., 2013. Reproducibility of a soil organic carbon fractionation method to derive RothC carbon pools. European Journal of Soil Science. doi: 10.1111/ejss.12088.

Scharnagl, B., Vrugt, J.A., Vereecken, H., Herbst, M., 2010. Information content of incubation experiments for inverse estimation of pool sizes in the Rothamsted carbon model: a Baysian approach. Biogeosciences 7, 763-776.

Skjemstad, J.O., Spouncer, L.R., Cowie, B., Switf, R.S., 2004. Calibration of the Rothamsted organic carbon turnover model (RothC ver. 26.3), using measurable soil organic carbon pools. Aust. J. Soil Res. 42, 79-88.

Schmidt, M.W.I, Torn, M.S., Abiven, S., Dittmar, T., Guggenberger, G., Janssens, I.A., Kleber, M., Kögel-Knabner, I., Lehmann, J., Manning, D.A.C., Nannipieri, P., Rasse, D.P., Weiner, S., Trumbore, S.E., 2011. Persistence of soil organic matter as an ecosystem property. Nature 478, 49-56. doi:10.1038/nature10386

Smith, P., Smith, J.U., Powlson, D.S., McGill, W.B., Arah, J.R.M., Chertov, O.G., Coleman, K., Franko, U., Frolking, S., Jenkinson,D.S., Jensen, L.S., Kelly, R.H., Klein- 
Gunnewiek,H., Komarov, A.S., Li, C.,Molina, J.A.E.,Mueller, T., Parton, W.J., Thornley, J.H.M., Whitmore, A.P., 1997. Acomparison of the performance of nine soil organic matter models using datasets from seven long-term experiments. Geoderma 81, $153-225$

Smith, J.U., Smith, P., Monaghan, R., Macdonald, A.J., 2002. When is a measured soil organic matter fraction equivalent to a model pool? European Journal of Soil Science $53,405-416$.

Steinmann, T., Welp, G., Holbeck, B., Amelung, W., 2016a. Long-term development of organic carbon contents in arable soil of North Rhine-Westphalia, Germany, 1979-2015. European Journal of Soil Science 67, 616-623.

Steinmann, T., Welp, G., Wolf, A., Holbeck, B., Große-Rüschenkamp, T., Amelung, W., 2016b. Repeated monitoring of organic carbon stocks after eight years reveals carbon losses from intensively managed agricultural soils in Western Germany. J. Plant Nutr. Soil Sci. 179, 355-366.

Storkey, J., Macdonald, A.J., Bell, J.R., Clark, I.M., Gregory, A.S., Hawkins, N.J., Hirsch, P.R., Todman, L.C., Whitmore, A.P., 2016. The Unique Contribution of Rothamsted to Ecological Research at Large Temporal Scales. Advances in Ecological Research (eds: A.J. Dumbrell, R.L. Kordas and G. Woodward), Vol 55, Chapter 1, (Academic Press), pp.3-42.

Taghizadeh-Toosi, A., Christensen, B.T., Hutchings, N.J., Vejlin, J., Kätterer, T., Glendining, M., Olesen, J.E., 2014. C-TOOL: A simple model for simulating whole-profile carbon strorage in temperate agricultural soils. Ecological Modelling 292, 11-25.

Weihermüller, L., Graf, A., Herbst, M., Vereeecken, H., 2013. Simple pedotransfer functions to initialize reactive carbon pools of the RothC model. European Journal of Soil Science 64, 567-575. doi: 10.1111/ejss.12036

Wendling, U., 1995. Berechnung der Gras-Referenzverdunstung mit der FAO PenmanMonteith-Beziehung. Wasserwirtschaft 85, 602-604.

Wutzler, T., Reichstein, M., 2007. Soils apart from equilibrium - consequences for soil carbon balance modelling. Biogeosciences 4, 125-136. 
Xu, X., Liu, W., Kiely, G., 2011. Modeling the change in soil organic carbon of grassland in response to climate change: Effects of measured versus modelled carbon pools for initializing the Rothamsted carbon model. Agriculture, Ecosystems and Environment $140,372-381$.

Zimmermann, M., Leifeld, J., Schmidt, M.W., Smith, P., Fuhrer, J., 2007. Measured soil organic matter fractions can be related to pools in the RothC model. European Journal of Soil Science 58, 658-667. 
Table 1

Characteristics of the long-term experimental sites; TOC is total organic carbon

\begin{tabular}{|c|c|c|c|c|c|}
\hline & Dikopshof & Duelmen & Poppelsdorf & Meckenheim & Hoosfield \\
\hline tart/end & $1904-2010$ & 1958 & $1908-2010$ & $1962-2010$ & 1852 \\
\hline \multirow[t]{4}{*}{ eatments* } & -MF/-FYM & -MF/-FYM & $+\mathrm{MF} /+\mathrm{FYM}_{20}$ & $+\mathrm{MF} /-\mathrm{FYM}$ & $+\mathrm{N} /-\mathrm{FYM}$ \\
\hline & $-\mathrm{MF} /+\mathrm{FYM} \mathrm{M}_{20}$ & $+\mathrm{MF} / \mathrm{FYM}$ & & $+\mathrm{MF} /+\mathrm{FYM}_{20}$ & $+\mathrm{N} /+\mathrm{FYM}_{1852}$ \\
\hline & $+\mathrm{MF} / \mathrm{FYM}$ & $+\mathrm{MF} /+\mathrm{FYM}_{25}$ & & $+\mathrm{MF} /+\mathrm{FYM}_{40}$ & $+\mathrm{N} /+\mathrm{FYM}_{2001}$ \\
\hline & $+\mathrm{MF} /+\mathrm{FYM}_{20}$ & & & & \\
\hline 'OC samplings & 6 & 15 & 2 & 4 & 6 \\
\hline óTOC & $0.76-1.25(2009)$ & $0.91-1.06(2011)$ & $1.33(2010)$ & $1.09-1.48(2006)$ & $2.02-3.40(2012)$ \\
\hline orth & $50^{\circ} 48^{\prime} 28.8^{\prime \prime}$ & $51^{\circ} 50^{\prime} 24.2^{\prime \prime}$ & $50^{\circ} 43^{\prime} 32.3^{\prime \prime}$ & $50^{\circ} 37^{\prime} 18.1^{\prime \prime}$ & $51^{\circ} 48^{\prime} 42.6^{\prime \prime}$ \\
\hline rest & $6^{\circ} 57^{\prime} 11.1 "$ & $7^{\circ} 15^{\prime} 23.6^{\prime \prime}$ & $7^{\circ} 5^{\prime} 9.6^{\prime \prime}$ & $6^{\circ} 59^{\prime} 33.1 "$ & $0^{\circ} 22^{\prime} 33.8^{\prime \prime}$ \\
\hline reter a.s.l. & 67 & 78 & 60 & 180 & 115 \\
\hline oil texture & loamy silt & loamy sand & silty loam & clay silt & loam \\
\hline lay \% mass & 15 & 5 & 17 & 18 & 23 \\
\hline VRB soil group & Luvisol & Stagnic Cambisol & Luvisol & Cambisol & Chromic Luvisol \\
\hline spsoil cm & 30 & 30 & 32 & 30 & 23 \\
\hline recipitation & $643^{* *}$ & $881^{* *}$ & $650^{* *}$ & $664 * *$ & $704 * * *$ \\
\hline$\left.n m y^{-1}\right)$ & & & & & \\
\hline smperature $\left({ }^{\circ} \mathrm{C}\right)$ & $10.1 * *$ & $10.0^{* *}$ & $10.4 * *$ & $9.7 * *$ & $9.3 * * * *$ \\
\hline
\end{tabular}

$\mathrm{MF}=$ mineral fertilizer, $\mathrm{N}=$ nitrogen, $\mathrm{FYM}=$ farmyard manure, $* *$ mean 1961-2010***mean 1971-2000 **** Coleman and Jenkinson, 2005 


\section{Table 2}

Mean $\mu$ and standard deviation $\sigma$ of fractions and pools; $t$-value of the unpaired t-test and error probability $p$

\begin{tabular}{lcccc}
\hline & $\begin{array}{c}\mu \\
\mathrm{t} \mathrm{ha}^{-1}\end{array}$ & $\begin{array}{c}\sigma \\
\mathrm{t} \mathrm{ha}^{-1}\end{array}$ & $t$ & $p$ \\
\hline \multicolumn{5}{c}{ longterm sites $\mathrm{n}=35$} \\
TOC $_{\text {measured }}$ & 50.3 & 17.9 & & \\
TOC $_{\text {model }}$ & 49.3 & 17.9 & 0.25 & 0.40 \\
$\mathrm{f}_{\text {POM }}$ & 8.1 & 4.2 & & \\
RPM & 8.1 & 4.9 & 0.03 & 0.49 \\
$\mathrm{f}_{\text {HUM }}$ & 35.0 & 12.4 & & \\
HUM & 36.8 & 13.6 & 0.58 & 0.28 \\
& intensive monitoring sites $\mathrm{n}=54$ & \\
$\mathrm{f}_{\text {POM }}$ & 10.7 & 4.6 & & \\
RPM & 10.0 & 3.7 & 0.91 & 0.18 \\
$\mathrm{f}_{\text {HUM }}$ & 44.4 & 14.4 & & \\
HUM & 48.7 & 16.1 & 1.50 & 0.07
\end{tabular}

$\mathrm{TOC}=$ total organic carbon, $\mathrm{f}_{\mathrm{POM}}=$ particulate organic matter fraction, $\mathrm{RPM}=$ resistant plant material pool, $\mathrm{f}_{\mathrm{HUM}}=$ humus fraction, $\mathrm{HUM}=$ humus pool 


\section{Table 3}

Pearson correlation coefficient $r$, mean absolute error MAE, root mean square error RMSE and mean error ME between fractions and model pools; all correlations significant at $\mathrm{p}<$ 0.0005

\begin{tabular}{lcc}
\hline & \multicolumn{2}{c}{ intensive monitoring sites } \\
\hline $\mathrm{n}=54$ & $\mathrm{f}_{\mathrm{POM}} / \mathrm{RPM}$ & $\mathrm{f}_{\mathrm{HUM}} / \mathrm{HUM}$ \\
\cline { 2 - 3 } $\mathrm{r}$ & 0.73 & 0.91 \\
$\mathrm{MAE}\left(\mathrm{t} \mathrm{ha}^{-1}\right)$ & 2.40 & 5.50 \\
$\mathrm{RMSE}\left(\mathrm{t} \mathrm{ha}^{-1}\right)$ & 3.19 & 7.81 \\
$\mathrm{ME}\left(\mathrm{t} \mathrm{ha}^{-1}\right)$ & 0.73 & -4.39 \\
& longterm experiments & \\
\hline $\mathrm{n}=35$ & $\mathrm{f}_{\mathrm{POM}} / \mathrm{RPM}$ & $\mathrm{f}_{\mathrm{HUM}} / \mathrm{HUM}$ \\
$\mathrm{r}$ & 0.81 & 0.94 \\
$\mathrm{MAE}\left(\mathrm{t} \mathrm{ha}^{-1}\right)$ & 2.07 & 3.84 \\
$\mathrm{RMSE}\left(\mathrm{t} \mathrm{ha}^{-1}\right)$ & 2.85 & -1.80 \\
$\mathrm{ME}\left(\mathrm{t} \mathrm{ha}^{-1}\right)$ & 0.03 & 4.96 \\
\hline
\end{tabular}




\section{FIGURE CAPTIONS}

Figure 1. Location and total organic carbon (TOC) stocks of the intensive monitoring sites. Ternary plot shows textural composition.

Fig 2. Measured (dots) and simulated (lines) total organic carbon stocks of the long-term experimental sites over time. Error bars represent measurement standard deviations, $\mathrm{MF}=$ mineral fertilizer, $\mathrm{N}=$ nitrogen, $\mathrm{FYM}=$ farmyard manure.

Fig 3. Inversely estimated organic carbon stocks in the decomposable plant material (DPM), resistant plant material (RPM), biomass (BIO), humus (HUM) and inert organic matter (IOM) pool of the intensive monitoring sites in 2010.

Fig 4. Long-term experimental sites model vs. measured total organic carbon (TOC), resistant plant material (RPM) pool vs. particulate organic matter fraction ( $\left.f_{\mathrm{POM}}\right)$, humus (HUM) pool vs. humus fraction $\left(\mathrm{f}_{\mathrm{HUM}}\right)$ and linear fits. Dynamic RothC model runs were carried out to infer the pools. Shaded areas represent the $95 \%$ confidence range of the fit, $\mathrm{R}^{2}=$ coefficient of determination; all correlations significant at $\mathrm{p}<0.0005$.

Fig 5. Intensive monitoring sites resistant plant material (RPM) pool vs. particulate organic matter fraction $\left(f_{\mathrm{POM}}\right)$, humus $(\mathrm{HUM})$ pool vs. humus fraction $\left(\mathrm{f}_{\mathrm{HUM}}\right)$ and linear fits. Shaded areas represent the $95 \%$ confidence range of the fit, $\mathrm{R}^{2}=$ coefficient of determination; all correlations significant at $\mathrm{p}<0.0005$.

Fig. 6 Long-term experimental sites model vs. measured resistant plant material (RPM) pool vs. particulate organic matter fraction ( $\left.\mathrm{f}_{\mathrm{POM}}\right)$ and linear fits. RothC model runs were carried out assuming equilibrium. Shaded areas represent the 95\% confidence range of the fit, $\mathrm{R}^{2}=$ coefficient of determination; correlation significant at $\mathrm{p}<0.0005$. 
Fig. 7 Hoosfield long-term experiment particulate organic matter fraction ( $\left.f_{P O M}\right)$, humus fraction ( $\left.\mathrm{f}_{\mathrm{HUM}}\right)$ and respective model pools resistant plant material (RPM) and humus (HUM); model pools are shown as lines; $\mathrm{N}=$ nitrogen, $\mathrm{FYM}=$ farmyard manure. 
Fig. 1

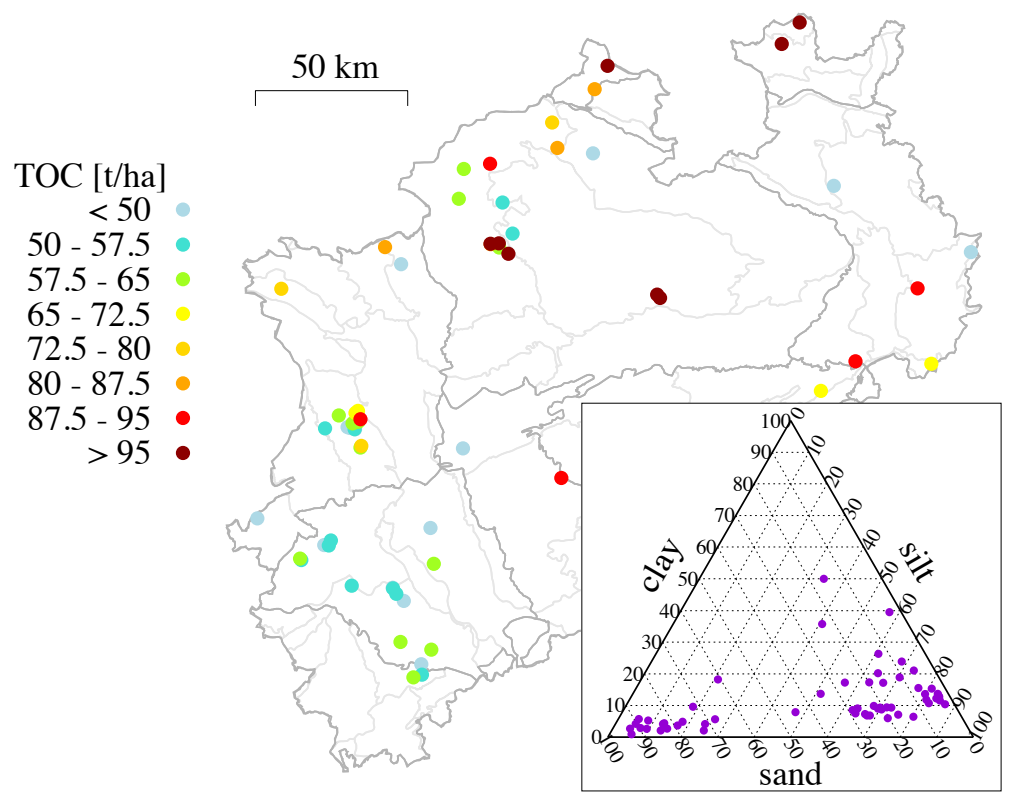


Fig. 2
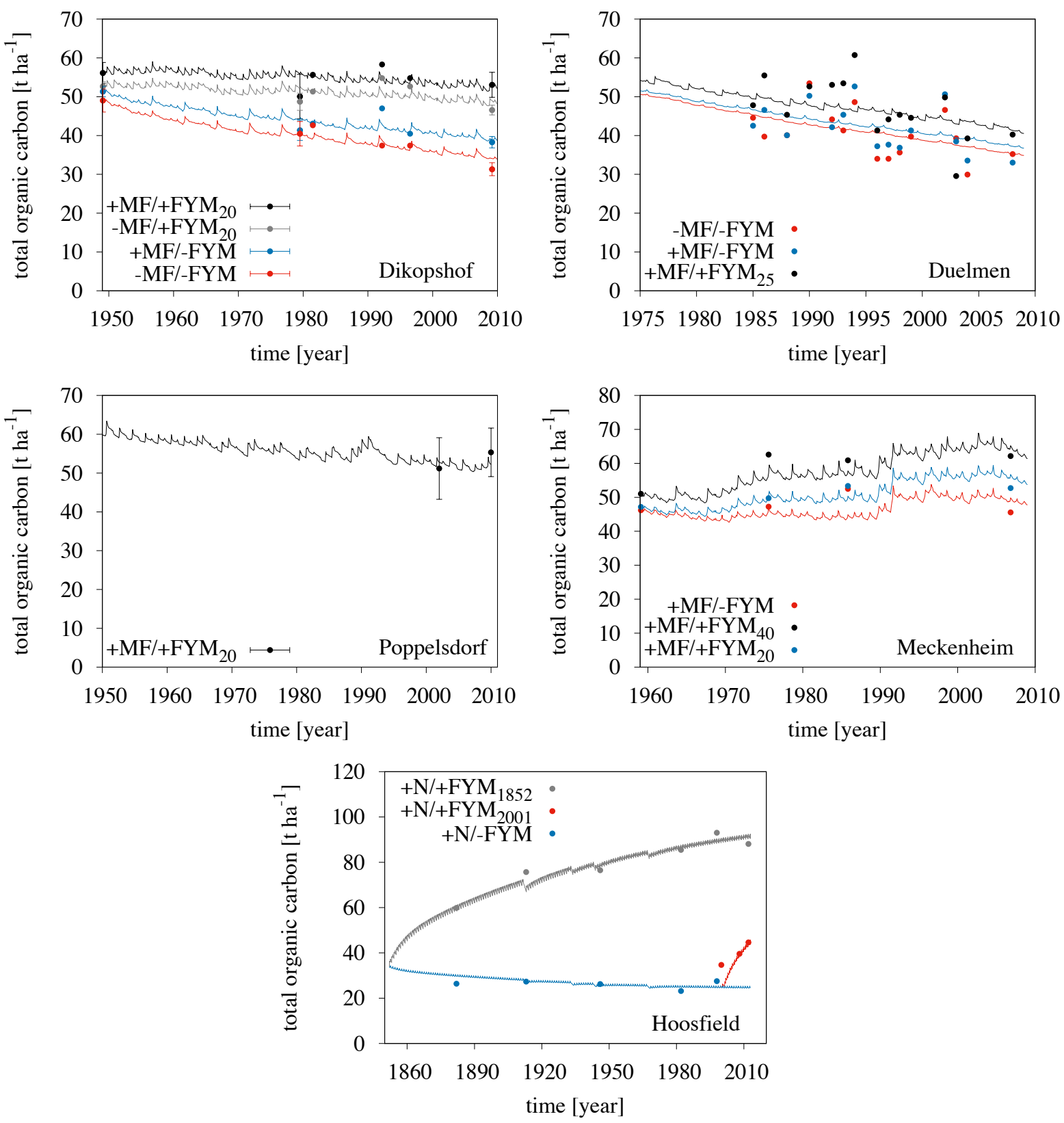
Fig. 3

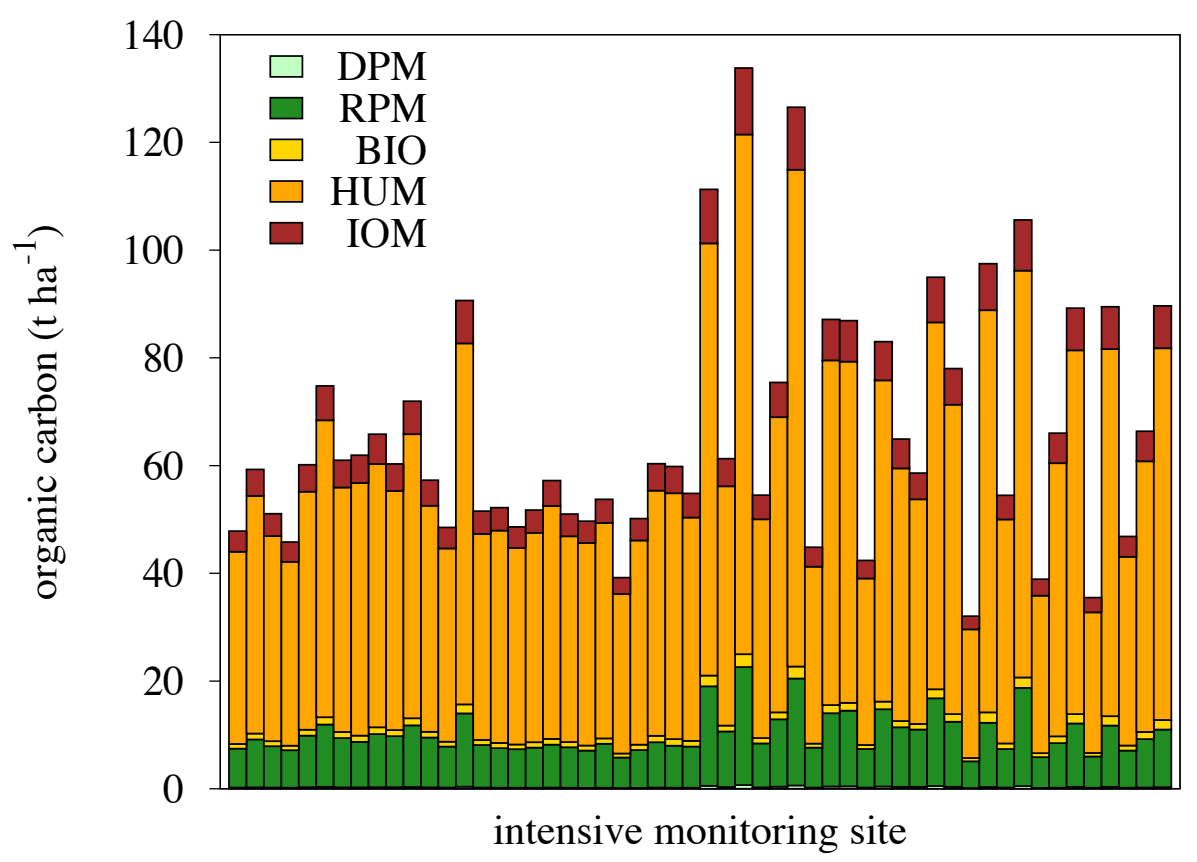



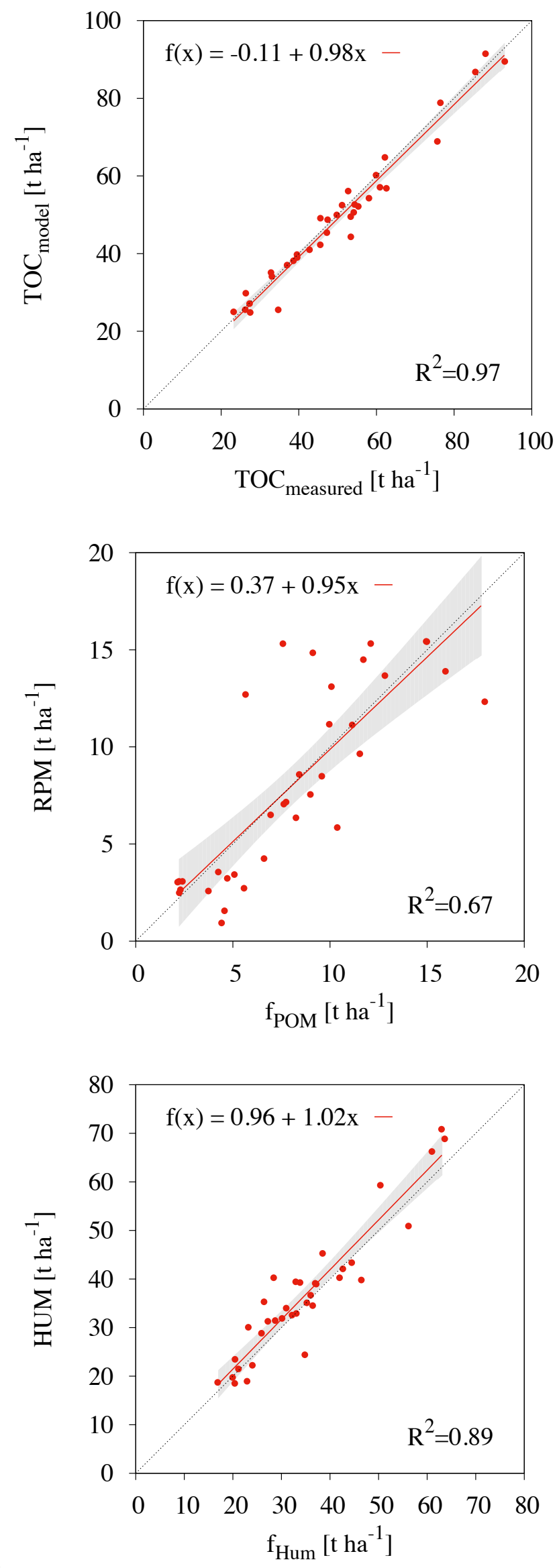

Fig. 4 
Fig. 5
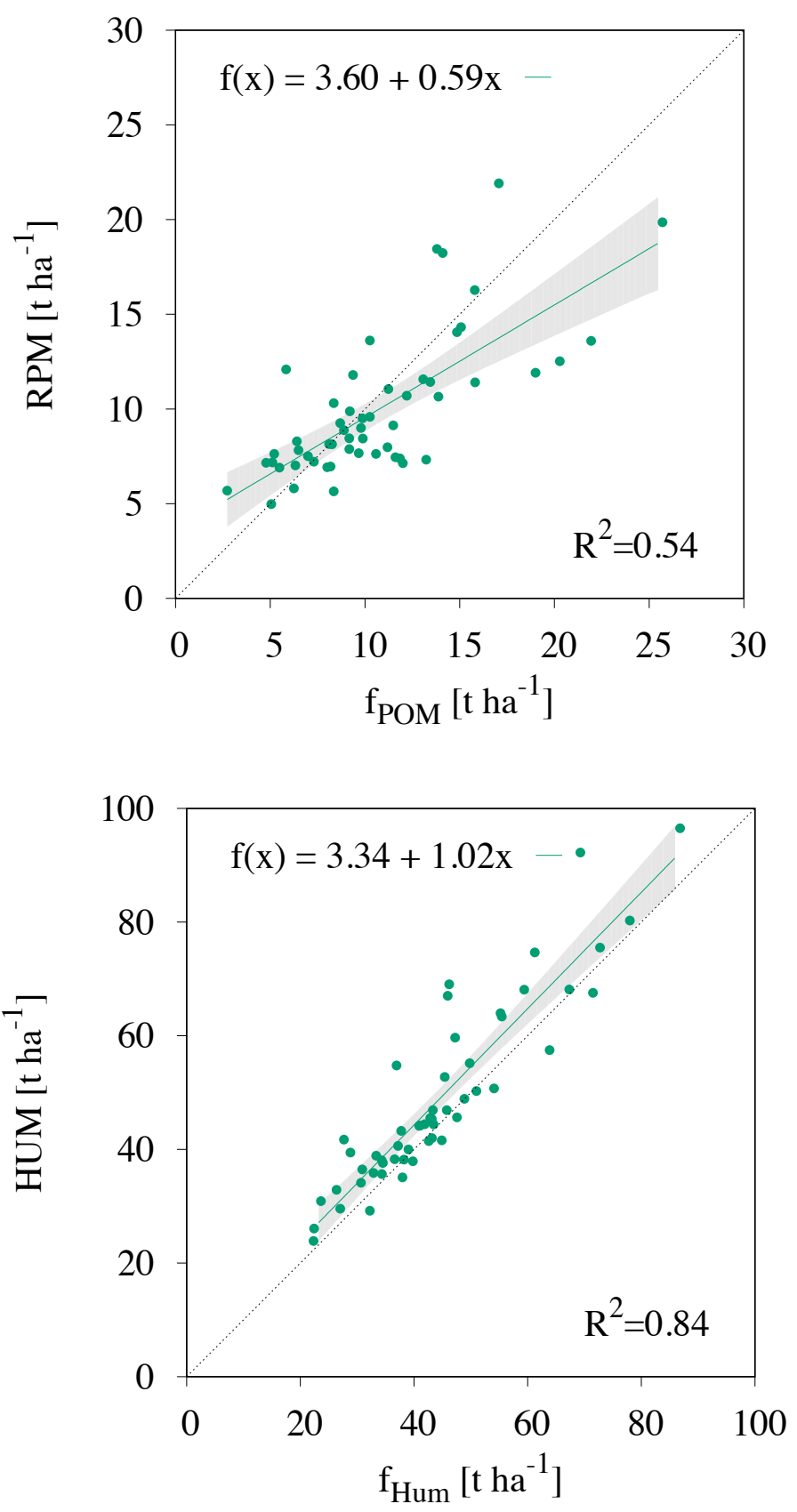
Fig. 6

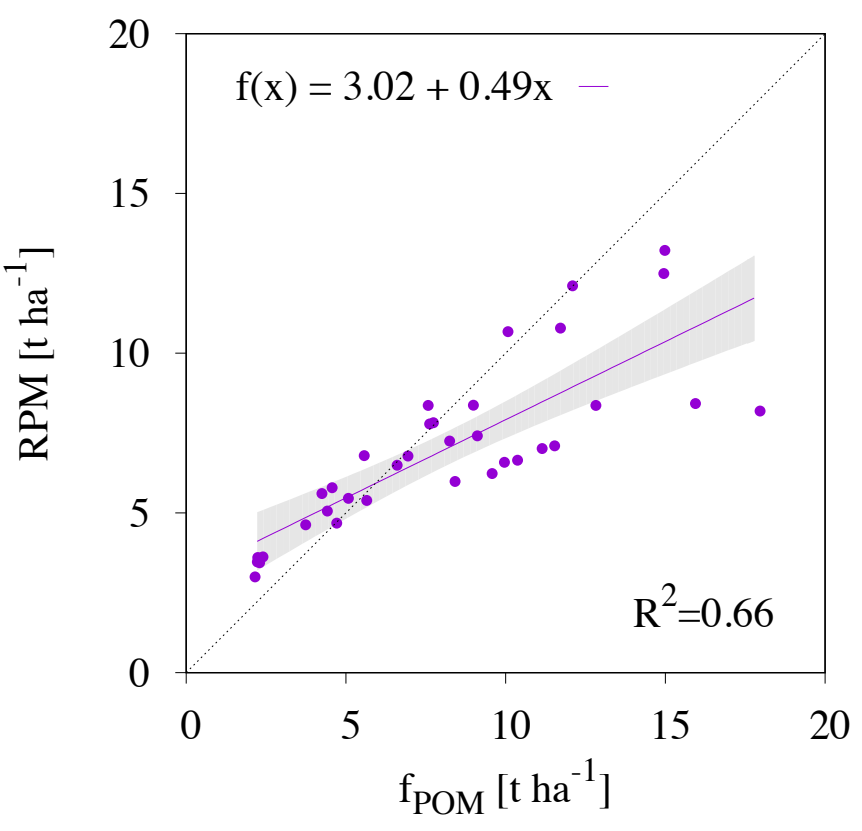


Fig. 7

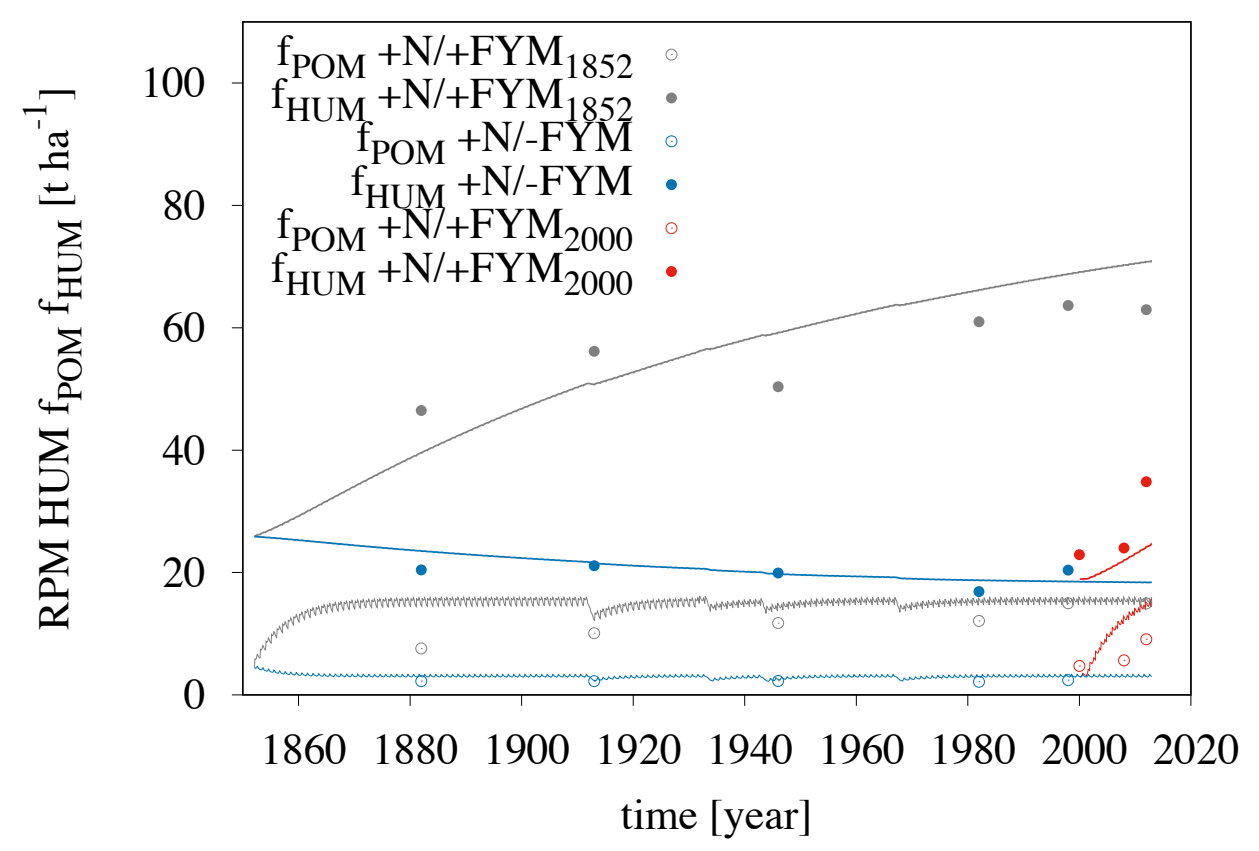

